\title{
It's Not Just about Drawing and Language ... It's Really about Reconceptualizing the Roles of Nature and Nurture
}

\author{
Commentary on Cohn
}

\section{R. Breckinridge Church}

Northeastern Illinois University, Chicago, III., USA

\author{
Key Words \\ Artistic development - Drawing ability · Language development
}

'Explaining "I can't draw" ' by Neil Cohn [this issue] presents a very interesting review and theoretical perspective on the 'drop-off' in drawing ability that occurs at puberty. The title 'I can't draw' immediately resonated with me because I really can't draw. My mother, on the other hand, was an artist - she really could draw. She could draw pictures that accurately represented the images that she intended to represent. My drawings are those classic stick figure people and rectangle houses topped by a triangle that Cohn talks about as being part of a common (possibly universal) graphic lexicon. My explanation for why I can't draw is that I didn't inherit my mother's special 'artistic' genes. So there you have it: the very theoretical bias that underlies people's beliefs about the development of drawing - in my own backyard, if you will. Cohn is suggesting that this is our belief about being able to draw - it is an entity that is fixed.

This belief that certain psychological characteristics are genetically determined and to some degree fixed is pervasive, but not for all cultures. Take, for example, math ability. Although this attitude may be changing slightly, individuals in the United States tend to believe that math ability is a fixed and genetically determined skill; some people are just good at math, and some just are not. I say, 'I just can't draw,' and I also have said, 'I am simply not good at math.' I can't tell you how many students in my statistics classes are certain that they will not be successful because, well ... they are just not good at math while also maintaining that they are good with people (another skill that some see as fixed and genetically determined; and that is why they are Psychology majors). This set of explanations about math performance common to my American undergraduates is not shared to the same degree by students and their par-

\begin{tabular}{ll}
\hline KARGER & $\odot$ 2012 S. Karger AG, Basel \\
Fax $+41613061234-716 X / 12 / 0554-0199 \$ 38.00 / 0$ \\
$\begin{array}{l}\text { E-Mail karger@karger.ch } \\
\text { www.karger.com }\end{array}$ & $\begin{array}{l}\text { Accessible online at: } \\
\text { www.karger.com/hde }\end{array}$
\end{tabular}

R. Breckinridge Church

Northeastern Illinois University

Department of Psychology, 5500 North St. Louis Avenue Chicago, IL 60625-4699 (USA)

Tel. +1 773442 5837, E-Mail b-church1@ neiu.edu 
ents and teachers in other cultures [Chen \& Stevenson, 1995]. Math teachers (and parents) in China, for example, place much less emphasis upon fixed innate abilities and assume that almost everyone has the capacity to do well in math. However, to perform well in math requires a lot of hard work [Hess, Chang, \& McDevitt, 1987]. The relative emphasis upon fixed abilities versus focused effort brings to mind Carol Dweck's [2000] self theory of motivation in which she makes a distinction between an entity orientation (which she applies to beliefs about intelligence) and a mastery orientation toward one's performance and achievement. With the entity orientation, one attributes success and failure to enduring aspects of the self. The result is that, in the face of failure in performance (e.g., failure to draw or do well in a statistics class), one gives up. This applies to me and drawing and to a majority of students in United States math classrooms. In contrast, according to Dweck, someone with a mastery orientation attributes success and failure to the amount of effort expended, and a person with this belief will persist in the face of failure. The mastery orientation seems to apply to students in Chinese math classrooms. The mastery orientation is also the perspective that Cohn wants us to adopt with respect to drawing, and he provides some compelling cross-cultural evidence suggesting that we need to rethink our notions about artistic ability. I would like to argue that Cohn's thesis should make us rethink our notions about the mechanisms responsible for the development of a lot of other behaviors and skills as well (e.g., intelligence and math ability). Cohn takes a commonly misunderstood phenomenon, a failure to draw, and turns the typical explanation on its head. Cohn's account of artistic ability suggests a contemporary view of how nature and nurture intersect to determine behavioral development. For this reason, Cohn's paper can be viewed not just as an account of the development of drawing but also as representing a paradigmatic shift in the way we conceptualize the role of nature and nurture in development.

The argument in Cohn's paper is that the ability to draw 'drops off' around puberty. Interestingly, this drop-off phenomenon does not occur across all cultures. For example, children in Japan do not experience this drop-off in artistic ability. Thus, Cohn argues that this drop-off is best explained by an interaction between cultural input about drawing and an individual's natural proclivities for drawing. However, Cohn is not talking about specialized individual genetically determined proclivities but species-specific proclivities. The author suggests that there may be a period (a critical period possibly) during development such that, if appropriate input about drawing is not provided, drawing capacity declines or fails to progress. He draws from research on the acquisition of language in which a similar phenomenon occurs when deprivation of language input results in impoverished language development. Cohn uses Susan Goldin-Meadow's conceptualization of language acquisition to explain the development of drawing. I summarize this conceptualization here.

\section{Fragile and Resilient Properties of Language and Drawing}

Goldin-Meadow [2003] conceptualizes language as being comprised of two properties: resilient and fragile. Essentially, Goldin-Meadow suggests that language can have both resilient properties, i.e., properties of language that will develop regardless of input, and fragile properties, i.e., language properties that will only develop if the individual is exposed to culturally conventionalized language input dur- 
ing a critical period of development. Her evidence comes from her research of the 'homesigns' of deaf children and 'Genie' [Curtiss, 1977], a girl who was raised in terrible, abusive circumstances, both examples of children who were not exposed to conventionalized language input during a critical period when input was necessary for full language development. For example, deaf children exhibit a gesture communication system that has basic language-like elements: (a) the use of basic syntax (systematic ordering of gesture words and morphemes) and (b) the use of a set of classifiers for shapes to refer to a variety of objects in the environment. The systematic ordering and classifier system used by the deaf children could be considered resilient, a rough template of a language system, intact despite no exposure to language. Fragile properties of language are those items in a language that are conventionalized (for example, prefixes, suffixes, subject-verb-object order) and that can only be learned if children are exposed to the arbitrary conventions of a particular language. There is a critical period for exposure to the conventional system. Once passed, the conventional system cannot be adopted, as evidenced by Genie who, despite intense practice with language once she was removed from her terrible living situation, could never acquire full-fledged language.

\section{The Parallel between Language and Drawing}

For the deaf children, systematic hand shapes (for example, a 'c-shaped' hand varying in diameter) are used to refer to long skinny things or short fat things, a flat hand is used to refer to vehicles, and wiggling fingers are used to refer to animate objects that walk. This classifier system is similar to the classifier system used in caveman art and what is described by Cohn as a basic drawing lexicon, a lexicon that will develop regardless of the type of drawing input received. Cohn argues that because Western art emphasizes fewer conventions for drawing, drawing remains tied to the resilient properties of drawing - the use of basic graphic lexicons like the ones I use to draw stick men and rectangle houses topped by triangles. In Japan, where there appears to be more exposure to a conventionalized system for drawing, drawing progresses and acquires conventionalized properties. Thus, more sophisticated, elaborate properties of drawing that follow the drawing conventions of a cultural style like Japanese anime cartoons (which always include people with really big eyes) are fragile properties, never to develop unless drawers are exposed to input during a critical period.

So Cohn argues that there are interesting parallels between language and drawing. I am going to address three main parallels and how they connect with other important theoretical notions relating to human development: (a) embodied cognition, (b) the evolution of language and (c) the role of resilient and fragile properties in other possible domains of behavior.

\section{Embodied Cognition Perspective}

The first parallel Cohn identifies is that language, gesture and drawing all have representational lexicons. Moreover, it is interesting how these representational systems are somewhat shared. The fact that humans have representational 


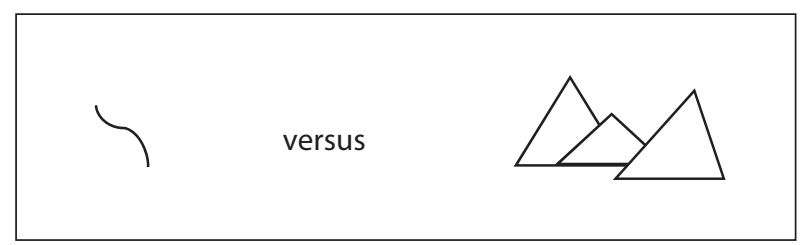

Fig. 1. Graphic depictions of a road and mountains.

lexicons to co-opt when attempting to express themselves suggests something interesting about the architecture of cognitive systems. Where does this architecture come from? Cohn's work does tie in with other theoretical perspectives, notably the embodied cognition perspective [Hostsetter \& Alibali, 2010; Kelly, Manning, \& Rodak, 2008; Lakeoff \& Nunez, 2000; Núñez, 2005]. The embodied perspective suggests that our representational systems are grounded in our actions and perceptual experiences. It is, therefore, not totally surprising that our expressive systems would also be grounded in a graphic lexicon that perhaps is different across language, gesture and drawing but also share some array of graphic representations. This is not determined by individual characteristics but, in fact, characterizes humans in general. This suggests architecture that is rooted in our genetic blueprint. So one might ask then, what purpose would a graphic lexicon serve for human development?

\section{Evolutionary Perspective}

Cohn's account of the development of drawing also shares with other modes of expression, like language and gesture, an explanation grounded in an evolutionary perspective of language evolution [Armstrong \& Wilcox, 2007; Kelly et al., 2008]. This explanation is really tied in with the embodied-cognition perspective. It is suggested that the origin of language is gestural and depictive, coming out of manual actions and shared perceptions of our surroundings [Armstrong \& Wilcox, 2007]. Cohn suggests that:

For example, homesigns, sign languages, and even spoken languages such as Navajo and Japanese use 'classifier' systems that map a variety of meanings to basic shapes and image schemas [Armstrong \& Wilcox, 2007; Goldin-Meadow, 2003]. Similar mappings appear in the sand drawings of native Australians, where simple circles and lines can stand for any number of meanings [Munn, 1962, 1986], and with early stages in drawing development in which graphic marks map to basic shapes and volumes in the denotation system [Willats, 1997]. If, as Armstrong and Wilcox [2007] suggest, these classifier systems reflect basic persisting strategies of mapping form to meaning across modalities, they may be included as resilient properties of drawing as well.

These mappings of certain forms and meanings may have been critical for communication since the dawn of humans. Before verbal language systems evolved, humans had to be able to communicate about their surrounds and their actions per- 
taining to basic survival. How would you explain, for example, that a trek should involve going through lowlands rather than through mountains? You would have to be able to depict your two routes in graphic imagery that did not require artistic talent but would resonate with your fellow tribesmen: a picture of a winding path versus a picture of mountains (fig. 1).

\section{The Role of Resilient and Fragile Properties}

I would argue that a contemporary view of the intersection of nature and nurture has to consider the resilient-fragile conceptualization of behavioral traits or properties. This contemporary view rethinks an evolutionary perspective of development by considering the role of input but also rethinks the psychological perspective by considering the role of genetics. The dovetailing of these perspectives can be seen in the notion that a genetically determined trait assumes interaction with a certain type of input that will fine-tune the development of that trait, be it language or drawing. If that input is not provided, then we see an aborted developmental plan or a rough template of a skill [Zeigler \& Marler, 2008, with respect to the acquisition of birdsong].

How far can we apply this conceptualization? I think a number of developments can be explained this way, but I provide as an example the development of intelligence. We now describe IQ as being comprised of two components: fluid and crystallized. Some also refer to these components as nonverbal-verbal, where fluid-nonverbal intelligence reflects basic intellectual processes that are independent of culturally acquired information and crystallized-verbal intelligence is the knowledge that is accumulated from exposure to conventional (often culturally determined) input. These two IQ components can also be seen as resilient and fragile properties. Fluid or nonverbal IQ can be seen as resilient, remaining somewhat intact regardless of variation in input (i.e., impervious to cultural variation). On the other hand, crystallized or verbal IQ can be seen as fragile and, therefore, highly influenced by exposure to appropriate input during critical periods of development.

Finally, Cohn notes a very interesting cultural difference in assumptions about the development of drawing skill. It is a difference that is fascinating and begs the question: why? What purpose would these two perspectives on art skills (the Western entity orientation vs. the Eastern mastery orientation) serve for the different cultures? It is interesting that Japanese drawers are likely to adopt a conventionalized drawing system - imitating in collective fashion as one might predict in a collectivist society. Westerners, in their ruggedly individualistic way, resist drawing convention, preserving individualism. So how do these two cultural values serve these two cultures? These are questions that do not get addressed in Cohn's paper (nor did they need to be), but they are certainly interesting to ponder.

\section{References}

Armstrong, D. F., \& Wilcox, S. (2007). The gestural origin of language. Oxford: Oxford University Press.

Chen, C.S., \& Stevenson, H. (1995). Motivation in mathematics achievement: A comparative-study of Asian American, Caucasian American, and East-Asian high school students. Child Development, $66,1215-1234$. 
Curtiss, S. (1977). Genie: A linguistic study of a modern-day 'wild child'. New York: Academic Press.

Dweck, C. (2000). Self-theories: Their role in motivation, personality and development. Philadelphia: Taylor and Francis.

Goldin-Meadow, S. (2003). The resilience of language: What gesture creation in deaf children can tell us about how all children learn language. New York: Psychology Press.

-Hess, R., Chang, C., \& McDevitt, T. (1987). Cultural variations in family beliefs about children's performance in mathematics: Comparisons among People's Republic of China, Chinese American, and Caucasian American students. Journal of Educational Psychology, 79, 179-188.

Hostetter, A.B., \& Alibali, M.W. (2010). Language, gesture, action! A test of the gesture as simulated action framework. Journal of Memory and Language, 63, 245-257.

Kelly, S.D., Manning, S.M., \& Rodak, S. (2008). Gesture gives a hand to language and learning: Perspectives from cognitive neuroscience, developmental psychology and education. Language and Linguistics Compass, 2, 569-588.

Lakeoff, G., \& Nunez, R.E. (2000). Where mathematics comes from: How the embodied mind brings mathematics into being. New York: Basic Books.

Núñez, R. (2005). Do real numbers really move? Language, thought, and gesture: The embodied cognitive foundations of mathematics. In F. Iida, R. Pfeifer, L. Steels, \& Y. Kuniyoshi (Eds.), Embodied artificial intelligence (pp. 54-73). Berlin: Springer.

Zeigler, H.P., \& Marler, P. (2008). Neuroscience of birdsong. Cambridge: Cambridge University Press. 